\title{
Corrections
}

\section{Correction: Warren et al., Catecholamine-Mediated Increases in Gain Enhance the Precision of Cortical Representations}

In the article "Catecholamine-Mediated Increases in Gain Enhance the Precision of Cortical Representations" by Christopher M. Warren, ${ }^{1,2}$ Eran Eldar, ${ }^{3}$ Ruud L. van den Brink, ${ }^{1,2}$ Klodianna-Daphne Tona, ${ }^{1,2}$ Nic J. van der Wee, ${ }^{2,4}$ Eric J. Giltay, ${ }^{4}$ Martijn S. van Noorden, ${ }^{4}$ Jos A. Bosch, ${ }^{5,6}$ Robert C. Wilson, ${ }^{7}$ Jonathan D. Cohen, ${ }^{1,2}$ and Sander Nieuwenhuis, ${ }^{8,9}$ which appeared on pages $5699-5708$ of the May 25, 2016 issue, there was a mix-up in the affiliations for two of the authors, Dr. Jonathan Cohen and Dr. Sander Nieuwenhuis, and the first name of Ms. K.-D. Tona was misspelled. The corrected author list and affiliations is as follows: Christopher M. Warren, ${ }^{1,2}$ Eran Eldar, ${ }^{3}$ Ruud L. van den Brink, ${ }^{1,2}$ Klodiana-Daphne Tona, ${ }^{1,2}$ Nic J. van der Wee, ${ }^{2,4}$ Eric J. Giltay, ${ }^{4}$ Martijn S. van Noorden, ${ }^{4}$ Jos A. Bosch, ${ }^{5,6}$ Robert C. Wilson, ${ }^{7}$ Jonathan D. Cohen, ${ }^{8,9}$ and Sander Nieuwenhuis. ${ }^{1,2}$ Their affiliations are as follows: ${ }^{1}$ Department of Psychology, Leiden University, 2333 AK Leiden, The Netherlands, ${ }^{2}$ Leiden Institute for Brain and Cognition, Leiden University, Leiden, 2300 RC Leiden, The Netherlands, ${ }^{3}$ Wellcome Trust Centre for Neuroimaging, University College London, London WC1N 3BG, United Kingdom, ${ }^{4}$ Department of Psychiatry, Leiden University Medical Center, 2333 ZA Leiden, The Netherlands, ${ }^{5}$ Department of Clinical Psychology, University of Amsterdam, 1018 XA Amsterdam, The Netherlands, ${ }^{6}$ Mannheim Institute of Public Health, Heidelberg University, 68167 Mannheim, Germany, ${ }^{7}$ Department of Psychology, University of Arizona, Tucson, Arizona 85721, and ${ }^{8}$ Department of Psychology and, ${ }^{9}$ Princeton Neuroscience Institute, Princeton University, Princeton, New Jersey 08540. The author line has been corrected on the online PDF version.

DOI: 10.1523/JNEUROSCI.2001-16.2016

\section{Correction: Knoll et al., Quantitative Trait Loci and a Novel Genetic Candidate for Fear Learning}

In the article "Quantitative Trait Loci and a Novel Genetic Candidate for Fear Learning” by Allison T. Knoll, Lindsay R. Halladay, Andrew J. Holmes, and Pat Levitt, which appeared on pages 6258-6268 of the June 8, 2016 issue, the authors regret incorrectly inserting a middle initial for the third author. The corrected author line is: Allison T. Knoll, Lindsay R. Halladay, Andrew Holmes, and Pat Levitt, which has been corrected on the online PDF version.

DOI: 10.1523/JNEUROSCI.2012-16.2016 